\title{
Comparative Analysis and Assessment of States' Traffic Management Center Programs
}

\author{
Ardeshir Faghri ${ }^{1}$, Michael L. Vaughan ${ }^{2}$, Abebaw Berihun' ${ }^{1}$ \\ ${ }^{1}$ Department of Civil \& Environmental Engineering, University of Delaware, Newark, DE, USA \\ ${ }^{2}$ Office of the Interim Vice Provost for Diversity \& Inclusion, University of Delaware, Newark, DE, USA \\ Email: faghri@udel.edu,vaughan@udel.edu, abebaw@udel.edu
}

How to cite this paper: Faghri, A., Vaughan, M.L. and Berihun, A. (2021) Comparative Analysis and Assessment of States' Traffic Management Center Programs. Journal of Transportation Technologies, 11, 231249.

https://doi.org/10.4236/jtts.2021.112015

Received: March 22, 2021

Accepted: April 19, 2021

Published: April 22, 2021

Copyright $\odot 2021$ by author(s) and Scientific Research Publishing Inc. This work is licensed under the Creative Commons Attribution International License (CC BY 4.0).

http://creativecommons.org/licenses/by/4.0/

\begin{abstract}
This research presents a step-by-step guideline for traffic data collection standards set by the Institute of Transportation Engineers (ITE) and American Association of State Highway and Transportation Officials (AASHTO). This study reviews manual and automatic methods of traffic counting and provides detailed information on traffic volume and vehicle classification studies. This research also provides a detailed analysis of the Delaware Department of Transportation (DelDOT)-TMC (Transportation Management Center) websites and compares it to selected Department of Transportation websites of other states such as Vermont, Connecticut, New Jersey, Pennsylvania, California, Texas, and Virginia. The purpose of the comparison is to analyze the data sources; user friendliness, accessibility, types of data available, presentation formats, and style for each state to determine how they compared to DelDOT-TMC. Although there were some similarities, the findings suggest that two major differences are present. The overall results revealed that DelDOT-TMC provides limited traffic and roadway weather data, and presentation formats to the public as compared to the other states. Further, a unitless variable, called the Capacity Factor (Q), has been developed within this study to represent this relative comparison. This study shows that DelDOT TMC performs well within the group of selected states and better than selected states of similar size and most selected states of larger size; where only Virginia performs better then DelDOT TMC. DelDOT TMC does not perform as well as selected neighboring states; however, it performs in an acceptable range relative to neighboring states.
\end{abstract}

\section{Keywords}

Transportation Management Center, Comparison, Evaluation, Data Collection, Case Study 


\section{Introduction}

Due to the population increase throughout the United States, transportation networks are congested daily, especially in morning and afternoon peak hours [1] [2] [3] [4] [5]. To avoid congested or closed routes, vehicle drivers typically rely on accurate and real-time traffic information to navigate their trip [6]-[11].

During the past decade, technology has altered the way in which traffic data is collected and disseminated. Technology, especially mobile technology, is rapidly changing how people consume and use traffic information [12] [13] [14] [15] [16]. With most drivers and public transit users relying on the Internet and smartphones to plan out their day, knowing the traffic and roadway weather conditions ahead of time has become a daily necessity before heading out on the road [17].

DelDOT maintains over $90 \%$ of the roads throughout the state of Delaware [18]. Under DelDOT, TMC (Transportation Management Center) is a statewide 24 hour, seven days a week emergency operation center that coordinates and manages DelDOT's response to any incident or event that influences Delaware's multimodal transportation system [18]. DelDOT-TMC is responsible for collecting, processing, analyzing, and disseminating traffic and roadway weather data to the public. It provides real-time travel information to allow the public to make informed decisions concerning travel route, travel time, and modal choice. Although TMC collects various types of traffic data, there are limitations in the information and presentation formats that are provided for the intended user.

Since its inception, DelDOT-TMC has been collecting, analyzing, and disseminating traffic and roadway weather data for distribution to transportation professionals, academia, as well as the general public. TMC is currently providing real-time traffic data through various platforms, including, smartphone applications, travel advisory radio, social media sites, various websites, and interactive maps that depict real-time traffic counts and incidents. With that said, the utilization and usability of this information by its intended user is largely unknown.

Although the information that TMC collects and disseminates is useful to the general public, this information lack historical details, i.e. traffic volume, roadway occupancy, delay, speed, classification, travel time, trip distribution, origindestination in various formats, which would serve to enhance overall robustness and usefulness. The collection and provision of these types of detailed historical data is crucial for further traffic studies and analysis that are often conducted by the different divisions in DelDOT, academia, and state agencies. The data can be used for simulation model input, completing Project Study Reports and other types of transportation planning and analysis documents [19] [20]. This study suggests that TMC's website does not provide detailed historical traffic data in different presentation styles and formats. Exporting historical and real-time data in various forms (i.e. MS Excel spreadsheet, MS Word, Shapefiles, Tables, Charts) are necessary for professionals and researchers who wish to utilize raw data to 
analyze the performance of highways and transit facilities [21] [22] [23].

The purpose of this study is to thoroughly examine TMC's data processing methods and distribution related to traffic and roadway weather data. Further, this study examines the extent to which the public uses DelDOT-TMC's traffic and roadway weather data. This study also examines the personal use experiences of the public regarding each of DelDOT's products. A comparison and an examination will also be conducted between states to determine how DelDOT-TMC performs relative to TMC entities from other states. As previously stated, DelDOT-TMC's methods of presenting and providing traffic and roadway weather historical and real-time data to the public are limited. By thoroughly comparing and examining the different aspects of DelDOT-TMC, this study hopes to provide clarity as to why limited traffic data and formats is provided for public consumption.

Although there are various types of traffic data that engineers and planners collect, this paper focuses only on traffic data collection for volume and vehicle classification studies. Traffic volume studies are conducted to determine the number, movement, and classification of roadway vehicles at a specific location. These data can help with the identification of critical flow time periods, assessment of the influence of large vehicles or pedestrians on vehicular traffic flow, as well as, documentation of traffic volume trends. The study presents the comparative research of the DelDOT-TMC data presentation as it relates to TMC entities for other selected states. This study focuses on are states of similar size to Delaware such as Vermont and Connecticut, neighboring states such as New Jersey and Pennsylvania; and large states such as California, Texas, and Virginia. The scope of this study is intended to examine how the websites and other internet assets of the select states present transportation data information to the intended users.

This research uses the AASHTO Guidelines for Traffic Data Programs and ITE Manual of Transportation Engineering Studies as guidance on the standard methods of conducting traffic data collection within the transportation field. This research will examine a few of the Department of Transportation websites for the selected states. The purpose of the examination is to analyze how these states provide historical and real-time traffic information to their intended users. The results will then be compared to the products and dissemination methods of DelDOT-TMC traffic and roadway weather data. Finally, to achieve the purpose and objectives of this investigation, this research will conduct public focused surveys to assess the utilization and usability of information collected and disseminated by DelDOT-TMC through the DelDOT Mobile App, WTMC 1380 AM travel advisory radio, DelDOT's public website, and DelDOT's social media.

The remaining part of this study is organized as follows. Section two focuses on the introduction to DelDOT-TMC and DelDOT-TMC data collection, analyses and dissemination methodologies. Section three uses the AASHTO Guidelines for Traffic Data Programs and ITE Manual of Transportation Engineering Studies to provide basic guidelines and detailed descriptions on the standard methodologies for data collection, processing, analyses and management. Sec- 
tion four discusses the differences and similarities of DelDOT-TMC product to those of other selected state TMCs. Here, this study examines the type of data sources and accessibility, these products used to disseminate data, and the presentation format that each of these state TMCs provide to their intended users. Section 5 discusses and provides conclusions.

\section{DelD0T Transportation Management Center (DELDOT-TMC)}

\subsection{Types of Data TMC Collects}

Delaware travelers have a lot of information available to them in various ways. DelDOT-TMC collects real-time traffic information, which contains live traffic video, travel time, travel advisories (incidents), travel restrictions and closures, traffic volume, roadway occupancy, delay, speed, classification, trip distribution, and origin-destination. Real-time roadway weather data, including air temperature, barometric pressure, relative humidity, precipitation type and volume, pavement temperature, as well as subsurface temperature are collected and disseminated through interactive maps [18].

Further, hydrological data, which includes stream and river depths, water velocity, and tide height, is also collected. To manage real-time and historical hydrological data, DelDOT installed a statewide network of flood monitoring equipment. Although TMC collects traffic and roadway weather data, hydrological data is collected by the United States Geological Survey (USGS) on behalf of DelDOT [18].

\subsection{DelD0T's TMC Data Collection Equipment}

DelDOT-TMC uses various types of devices and tools to collect automated data, which includes both fixed and portable sites. These tools and devices, which are mostly used for incident detection including control; information; and monitoring, are discussed below [18]:

- Variable speed limit (VSL) sign allows TMC to adjust the posted speed limit remotely. TMC uses these electronic signs to increase the traffic flow and reduce the risk of crashes due to congestion. Electronic signs are also used to provide information in support of incident management, construction activities, adverse environmental conditions, changes in traffic patterns, and special events.

- Weigh Station is used as a truck and commercial vehicle checkpoint along a highway. The purpose of a weight station is to inspect the weight of trucks and commercial vehicles. Weigh-in-motion technology is used to screen trucks for weight.

- Traffic Signals are responsible for controlling the flows of traffic. By monitoring traffic signals, TMC can adjust traffic patterns based on volume and speed data.

- HAWK signals are high-intensity beacons triggered by pedestrian requests at 
crosswalks to stop road traffic to allow pedestrians to cross safely.

- Variable message signs (VMS) display relevant information for motorists utilizing Delaware roadways. Variable message signs are electronic traveler information signs are used to provide information in support of incident management, construction activities, adverse environmental conditions, and changes in traffic patterns and special events.

- Dashboard cameras are attached to vehicles to capture live video and still photos. The other type of cameras that DelDOT-TMC possesses are fixed video cameras, primarily used for monitoring traffic conditions and verifying roadway incidents such as crash, disabled vehicle, construction, and maintenance activity.

- Computer-Aided Dispatch $(C A D)$ is centralized statewide control and management of the CAD to CAD connections with County Emergency Operations Centers (EOCs) and State Police.

- Signal System Loop Detectors are responsible for collecting real-time data along signalized corridors. The primary purpose of these detectors is to provide current traffic volumes so that TMC can use it to determine signal-timings.

- Microwave Detection (Wavetronix) allows TMC to detect vehicles by lane, to classify vehicles by length and, to provide real-time traffic volume, speed, and delay.

- Automatic Traffic Recorders (ATRs) is used to measure volume, class, and speed. Automatic electronic ATRs are installed in the road to collect data such as measure count, classification, and speed. The data is then recorded in memory so that the information can be downloaded and viewed for further analysis.

- Bluetooth detection is set-up to detect signals that are being emitted from discoverable Bluetooth devices within vehicles as the vehicles pass the Bluetooth monitoring station. This technology is also used to obtain real-time travel information such as average travel times, travel speeds, and travel patterns.

- Roadway Weather Information System ( $R W I S$ ) allows TMC to measure atmospheric pressure, water level and pavement conditions [24]. Water level conditions include air temperature, surface and subsurface temperature, dew temperature, relative humidity, wind direction, wind speed, wind gust, visibility, and precipitation.

- Hydrology Monitoring System is designed to monitor rainfall events. These are composed of a group of stations (gauges) that are arranged and operated to capture flooding and erosion.

\subsection{Telecommunication and Software}

After data collection, TMC uses the following transportation database and software to analyze the collected raw data. TMC uses software such as a traffic database (TransStat), internal user interface (Electronic Operations, EOPs), external user interface (Extranet), and an incident management system (Tracker) to col- 
lect, process, analyze, and distribute information to the public [18]. Tracker is a data system that DelDOT uses to automate the validation process of construction and incident information [18]. As per DelDOT's publication (4), TMC uses the internal user interface EOPs to monitor the traffic heartbeat (Figure 1).

\section{Volume and Classification Counts Studies}

\subsection{Introduction to Volume and Classification Counts}

The ITE manual provides various types of traffic studies, which includes volume, spot speed, travel-time and delay, intersection and driveway, inventories, traffic access and impact, parking, traffic accident, traffic conflict, pedestrian, traffic control device, public transportation, goods movement, and queuing [25]. However, according to AASHTO Guidelines for Traffic Data Program, there are four essential types of traffic studies that are collected by TMC: volume counts, classification counts, speed data, and weight data. Other types of traffic data collected by state DOTs comprise of speed, travel time, lane occupancy, and vehicle occupancy data. This report focuses on volume count and classification count studies [26]. Using the ITE Manual of Transportation Engineering Studies and AASHTO Guidelines for Traffic Data Program, this study examines the methods, procedures, equipment, personnel, and levels of training needed for traffic data collection.

\subsection{Coverage Counts}

Coverage count programs typically include weigh-in-motion (WIM), vehicle

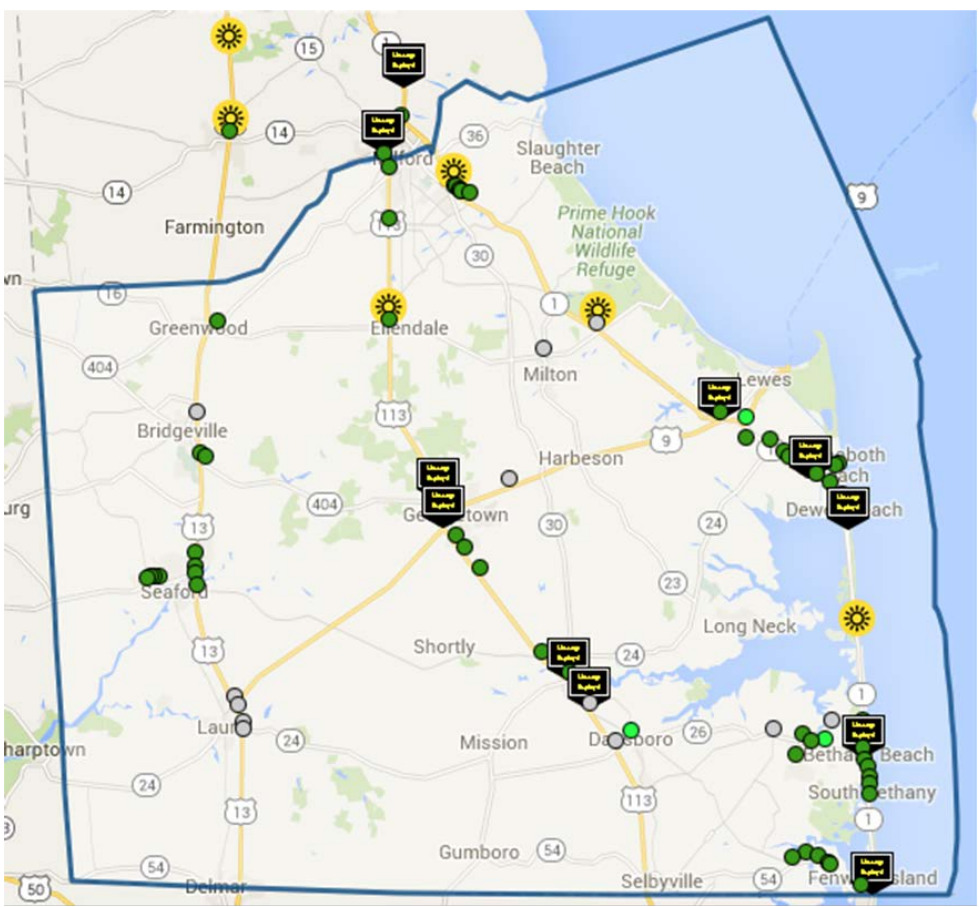

Figure 1. DelDOT monitoring devices used by TMC on DelDOT's TMC Website (https://tmc.deldot.gov/datamap). 
classification, volume, and speed data collection programs. The recommended short-term coverage counts sample size for traffic volume, and vehicle classification is based upon a system-wide statistical sample. The short-term volume, vehicle classification, and weigh-in-motion counts, and supplemental counts taken within the special needs part of the program comprise the coverage count program [26].

\subsection{Volume and Vehicle Classification Counts}

According to AASHTO Guidelines for Traffic Data Programs, the most basic form of traffic data collection is volume count. Volume counts are collected as a combination of continuous counts and short-term counts. Continuous counts are obtained from permanently installed equipment in, along, or above the roadbed that is operated continuously. Short-term counts are frequently collected through the use of pneumatic tubes gathering axle impulses that are factored in the later time. Short-term volume counts represent the bulk of any coverage count program [26].

\subsection{Methods of Counting}

There are two primary methods of conducting traffic volume count, are 1) manual observation and 2) mechanical or automatic recording. The vehicles stream is classified through either manual observation or automated equipment. Manual observation is short-term, and it is often based upon vehicle axle number and the vehicle body style. Automated equipment can be used continuously or for short-term periods. This particular equipment classifies vehicles through either axle distance or total vehicle length. Vehicle classification data can be aggregated to fulfill a volume count requirement. Some automated vehicle classification systems can also provide speed data [26].

\subsection{Reduction and Analysis of Traffic Volume}

After collection of traffic data, raw data must be reduced to a form appropriate for analysis. This reduction usually consists of the conversion of tally marks to numbers, summation of the data by calculating subtotals and totals, and arrangement the data into an acceptable format for analysis. The analysis may range from a simple extraction of descriptive information to a more sophisticated statistical treatment of the data. The review will depend on the type of study being conducted [25].

\subsection{Volume Data Presentations}

Traffic volume data may be portrayed in a number of ways. The selection of the method of presentation can depend on the audience and the objective for presenting the data. Analysts most often depict volume data in summary tables or one of several graphical forms. Graphs and charts are suitable for illustrating traffic volumes over time. Pie charts are useful to show proportions of volumes 
by vehicle type.

\subsection{Specific Counting Studies}

Traffic volume counting is not always a simple and straightforward task. Some types of volume studies are complex and challenging to perform. They require special preparations and trained observers. There are specific complex counting studies that challenge data collectors to conduct the studies, which include intersection counts, pedestrian counts, cordon counts, screen line counts, areawide counts and control counts [25].

\subsection{Traffic Data Reporting and Management}

After traffic data are collected, edited, and summarized, they are reported to users. Web-based portals are the current mechanism most widely used to disseminate traffic information. By using web-based portals, it is fairly simple to distribute traffic data is by generating the reports and printing them as PDF files. The public can then access these files on a website. Another option is to allow users to select these parameters and have the system create real-time reports. This option allows more flexibility in report creation but requires that the underlying report program allows this kind of parameterization. Many states provide webbased reporting tools that enable their users to generate reports over the Internet [26].

The day-to-day work of most state agencies often requires responding to internal and external requests for traffic information. Microsoft Office products, particularly word processors and spreadsheets, are a convenient way to perform this work. Some specialized reporting packages are explicitly designed for report preparation from an external database. These tools usually have both powerful report formatting capabilities and data manipulation tools. They allow custom functions, sub-reports, charting, and other skills. These tools also will allow the report format to be saved and used again for periodic reporting capabilities [26].

\section{Comparison of DelDOT-TMC to Selected States}

This section presents a comparative analysis of DelDOT-TMC products and data presentation formats relative to selected states that are similar in size to Delaware such as Vermont and Connecticut, neighboring states like New Jersey and Pennsylvania; and larger states such as California, Texas, and Virginia. This section will focus on traffic data, and it will examine the data source, accessibility, presentation formats, and styles for each of the selected states.

\subsection{Comparison by Data Source and Its Accessibility}

\subsubsection{DelDOT-TMC}

DelDOT collects, analyzes, manages, and disseminates historical and real-time traffic and roadway weather data. To provide real-time traffic and roadway weather data, DelDOT uses the following website: DelDOT's public website, TMC 
Extranet, "TMC Data Map," and "TMC Weather Summary."

DelDOT's public website and TMC Extranet website are accessible and user-friendly; however, the TMC Extranet website requires users to register before gaining access to the site. The March 13, 2018 "Integration of Operations and Planning Advisory Committee Meeting" document provides links to the "TMC Data Map" and "TMC Weather Summary" websites. These two websites revealed detailed traffic and roadway weather data; however, these sites are not accessible to the public through standard web browsing.

\subsubsection{Similar Size States (Vermont and Connecticut)}

The states of Vermont and Connecticut were chosen due to their similarity in size to Delaware. These two states also provide real-time traffic data through their websites, mobile applications, and social media sites.

The Vermont Agency of Transportation (VTrans) uses Transportation Data Management System, also known as TDMS, to disseminate various types of traffic data through its web-based interactive map. However, only two of the modules (TCDS and TMC) are accessible to the public. To obtain the other modules, as well as additional reports, VTrans requires that all individuals create a user account. VTrans provides a data website that is open to the public through “Transparency Public Information Portal." The open data portal allows users to download raw transportation data sets. VTrans also uses a website called "New England 511", which provides a map of real-time traffic information for three states (New Hampshire, Maine, and Vermont).

The Connecticut Department of Transportation (CTDOT) disseminates traffic data through its public website and the "CT Travel Smart" website. Both of these websites are available to the public, and have a very intuitive user interface. The CTDOT website provides links to some traffic and travels mobile apps such as Google maps, Waze, Transit App, Roadify, RoadAhead, and INRIX Traffic; however, RoadAhead highway exit finder application requires a fee of $\$ 1.99$ to download. All other CTDOT supported mobile applications are free.

VTrans and CTDOT also disseminate real-time traffic conditions through their social media sites. VTrans uses Twitter, Facebook, YouTube, and Flickr to provide traffic information to their users. CTDOT delivers information through Twitter and Facebook.

\subsubsection{Neighboring States (New Jersey and Pennsylvania)}

The NJDOT website provides traffic information through the following tabs; Functional Classification Maps, National Highway Systems (NHS), Public Roadway Mileage (HPMS), and Straight Line Diagrams; however, to use Straight Line Diagrams (Automated Straight Line Diagrams and New Jersey Roadway Video$\log$ ), users are required to install Microsoft Silverlight software. Once MS Silverlight is downloaded, traffic data by routes and municipality are easily attainable. The interactive map through the URL " 511 nj.org" provides additional travel and traffic information to the public. 
Pennsylvania Department of Transportation (PennDOT) uses its public website and "511PA Travel Info" website to monitor traffic information, facilitate safe traffic counting across the state, as well as provide traffic and GIS resources to the public.

Both NJDOT and PennDOT provide real-time traffic information through their hands-free mobile app, "SafeTripNJ" and "511PA Travel Info to Go". By utilizing the user's built-in GPS, smartphone applications for both states use the PA and NJ travel information data system to inform drivers on current traffic disruptions (construction, conjunctions, accidents, and others) that are within close range. These applications are free to download and fairly easy to use. When there is an incident nearby, both SafeTripNJ and "511PA Travel Info to Go" mobile apps broadcast traffic advisory. There is nothing to read, click, or scroll through to use these apps.

Both NJDOT and PennDOT also update the public about traffic conditions through the social media sites. NJDOT uses social media sites such as Facebook, Twitter, YouTube, Instagram, and ReadyNJ Blog. PennDOT uses Facebook, Twitter, YouTube, and Instagram to provide travel and traffic information to their intended users.

\subsubsection{Larger States (California, Texas, and Virginia)}

California Department of Transportation (Caltrans) obtains traffic data from the Caltrans Performance Measurement System (PeMS). Users are required to establish an online account to access or download traffic data through the PeMS web-based interface systems. Once a user establishes an account, they can immediately access PMS. The Caltrans website provides users with a variety of traffic data information.

Texas Department of Transportation (TxDOT) uses Traffic Count Database System (TCDS) to organize and distribute traffic count data. The TXDOT website provides a direct link to the DriveTEXAS website to access more real-time traffic conditions throughout the state.

Virginia Department of Transportation (VDOT) conducts a program where sensors gather traffic data that are in or along the state highway. "VDOT 511" website also provides real-time traffic and roadway weather. VDOT periodically produces booklets that consist of traffic data and estimates and then published on the department's website.

\subsection{Comparison by Data Types}

\subsubsection{DelDOT-TMC}

When it comes to real-time traffic information, TMC provides data such as traffic volume, roadway occupancy, delay, speed, travel time, travel advisories (incidents), travel restrictions and closures, construction projects, schedule of DART transit, traffic cameras, as well as variable message sign locations.

The DelDOT's public website and interactive map deliver real-time weather information such as charging station locations, roadway weather, water level, 
snow accumulation, and snow plow tracking. The roadway weather, for example, allows users to access real-time information about air temperature, dew temperature, relative humidity, wind speed, wind gust, wind direction, heat index, visibility, and precipitation.

The "TMC data map" website provides real-time traffic information including travel time, traffic cameras, traffic flows, tracker advisories, DART transit schedules, snow plow locations, as well as weather station locations through interactive travel maps.

The "TMC weather summary" website provides weather stations, surface and subsurface temperature, air temperature, relative humidity, dew temperature, precipitation, visibility, wind speed, wind gust, and wind direction. This roadway weather interactive map also presents hydrological information such as hydro stations, stream and river depth, water velocity, and tidal height in real-time.

\subsubsection{Similar Size States (Vermont and Connecticut)}

The VTrans TDMS currently offers two modules 1) Traffic Count Database System (TCDS), which contains both continuous and short-term counts and 2) TMC Turning Movement Count (TMC) modules. Through TCDS, VTrans organizes an agency's traffic count data. It allows users to upload data from a traffic counter; view graphs, list and report historical traffic count data; search for count data using either the database or the Google map; and print or export data to their computer. The AADT data represents a traffic count data report that can be viewed or downloaded from the VTrans' public website. These data reports are updated by VTrans every three-years.

Similar to VTrans, CTDOT also counts all of its state-maintained roadways once every three years to determine the average daily traffic (ADT) of the road. CTDOT provides ADT maps for traffic volumes at specific locations through an interactive map. It offers continuous count station spreadsheets, which contains an average hourly, daily, weekly, and monthly traffic counts. CTDOT also disseminates vehicle classification reports through its public website, "CT Travel Smart;" where, users can access information including travel speeds, camera imagery, incidents, roadwork, message signs, weather alerts, and weather forecasts.

\subsubsection{Neighboring States (New Jersey and Pennsylvania)}

NJDOT provides traffic information including traffic volume counts, vehicle classification, vehicle speed, truck weight, vehicle miles traveled, and highway functional classification. NJDOT also maintains a traffic-monitoring program consisting of continuous and short-term elements. The state's Traffic Monitoring System Map (TMSM) disseminates traffic data such as weigh-in-motion, 48 hrs-volume and classification, intersection count, seven days-volume, continuous volume, and data for ramps. Users can navigate daily or monthly weighin-motion data from the public website. Transportation data such as accidents, construction, congestion, road inventories, pavements, and safety are used to produce maps that support the department's work in planning, highway, rail, 
aviation, and maritime.

Pennsylvania Highway Statistics updates and summarize a variety of highway mileage and travel information annually and then reports the summary to the public. PennDOT collects and disseminates traffic data including volume, vehicle classification, highway functional classification, truck weight, and speed by state; county; and district. Both NJDOT and PennDOT provide real-time travel advisories through their hands-free mobile applications and social media sites.

\subsubsection{Larger States (California, Texas, and Virginia)}

Caltrans PeMS allows users to report on many performance measures including flow (volume), Annual Average Daily Traffic (AADT), Monthly Average Daily Traffic (MADT), Occupancy (percent time over detector), vehicle speed, Vehicle Miles Traveled (VMT), Vehicle Hours Traveled (VHT), Travel Time Index (TTI), delay (expressed in vehicle hours), lost productivity (shown in lane mile hours), and Level of Service (LOS). Through QuickMap app, Caltrans provides real-time traffic information including freeway speed, traffic camera snapshots, lane closures, incidents, highway information, changeable message signs, snow plows, Waze data (accidents, traffic jam, hazard, construction, and road closing) and others.

TxDOT provides various types of counts (volume, class, speed, gap, and others) that have been performed at a specific location over the years. Users can also view any AADT's that have been calculated for that location. In its TCDS module, there are four different report categories available to authorized users which are a single station, single day reports; single station, multiple day reports; multiple stations, multiple day reports; and "Report Center" reports.

VDOT periodically publishes booklets that list the type of traffic data that the department provides through its public website which includes AADT, average weekday traffic, peak hour, and peak direction factors. A summary report of the VMT within selected jurisdictions is also available. "VDOT 511" website also provides real-time traffic and roadway weather on the interactive map (map views). The website provides real-time roadway weather such as air temperature, dew point, relative humidity, wind speed, wind gusts, wind direction, visibility, precipitation, pavement temperature, and condition.

\subsubsection{Capacity Analysis for Selected States}

Figure 2 below shows the comparison of DelDOT-TMC to the select states TMC entities by the comparators; data sources, User Friendliness, Accessibility, Type of Data Available, and presentation formats. The overall results of the comparative analysis revealed that DelDOT-TMC and all of the select states provide a wide range of real-time traffic data through various sources include websites, mobile applications, travel advisory radios, and social media sites.

To aid in the comparisons in this study, we have development a methodology to analyze the capacity of TMC entities regarding data robustness and dissemination. The same data provided in Figure 2 will be used for this analysis. Each of 


\begin{tabular}{|c|c|c|c|c|c|c|c|c|}
\hline Description & DE & VT & CT & NJ & PA & $\mathrm{CA}$ & TX & VA \\
\hline \multicolumn{9}{|c|}{ Data S ources: } \\
\hline Websites & $\bar{Y}$ & $\bar{Y}$ & $\bar{Y}$ & $\bar{Y}$ & $\bar{Y}$ & $\bar{Y}$ & $\bar{Y}$ & $\bar{Y}$ \\
\hline External Database & $\bar{Y}$ & $\bar{Y}$ & $\bar{Y}$ & $\bar{Y}$ & $\bar{Y}$ & $\bar{Y}$ & $\bar{Y}$ & $\bar{Y}$ \\
\hline Mobile App & $\mathrm{Y}$ & $\mathrm{N}$ & $\mathrm{Y}$ & $\mathrm{Y}$ & $\mathrm{Y}$ & $\mathrm{Y}$ & $\mathrm{Y}$ & $\mathrm{Y}$ \\
\hline Travel Advisory Radio & $\mathrm{Y}$ & $\mathrm{N}$ & $\mathrm{N}$ & $\mathrm{Y}$ & $\mathrm{Y}$ & $\mathrm{N}$ & $\mathrm{N}$ & $\mathrm{Y}$ \\
\hline Social Media Sites & $\bar{Y}$ & $\mathrm{Y}$ & $\mathrm{Y}$ & $\bar{Y}$ & $\bar{Y}$ & $\bar{Y}$ & $\mathrm{Y}$ & $\mathrm{Y}$ \\
\hline \multicolumn{9}{|c|}{ User friendliness: } \\
\hline Websites & $\mathrm{Y}$ & $\mathrm{Y}$ & $\mathrm{Y}$ & $\mathrm{Y}$ & $\mathrm{Y}$ & $\mathrm{Y}$ & $\mathrm{Y}$ & $\mathrm{Y}$ \\
\hline External Database & $\mathrm{Y}$ & $\mathrm{Y}$ & $\mathrm{Y}$ & $\bar{Y}$ & $\mathrm{Y}$ & $\bar{Y}$ & $\mathrm{Y}$ & $\mathrm{Y}$ \\
\hline Mobile App & $\mathrm{Y} / \mathrm{N}$ & $\bar{N}$ & $\bar{Y}$ & $\bar{Y}$ & $\bar{Y}$ & $\bar{Y}$ & $\mathrm{~N}$ & $\bar{Y}$ \\
\hline Travel Advisory Radio & $\mathrm{Y}$ & $\mathrm{N}$ & $\bar{N}$ & $\bar{Y}$ & $\mathrm{Y}$ & $\mathrm{N}$ & $\mathrm{N}$ & $\bar{Y}$ \\
\hline Social M edia Sites & $\mathrm{Y}$ & $\bar{Y}$ & $\bar{Y}$ & $\bar{Y}$ & $\mathrm{Y}$ & $\bar{Y}$ & $\bar{Y}$ & $\bar{Y}$ \\
\hline \multicolumn{9}{|c|}{ Accessibility: } \\
\hline Websites & $\bar{Y}$ & $\mathrm{Y}$ & $\bar{Y}$ & $\mathrm{Y}$ & $\bar{Y}$ & $\mathrm{Y}$ & $\bar{Y}$ & $\mathrm{Y}$ \\
\hline External Dat abase & $\overline{Y / N}$ & $\mathrm{Y} / \mathrm{N}$ & $\bar{Y}$ & $\bar{Y}$ & $\bar{Y}$ & $\mathrm{Y} / \mathrm{N}$ & $\bar{Y}$ & $\mathrm{Y}$ \\
\hline Mobile App & $\mathrm{Y} / \mathrm{N}$ & $\mathrm{N}$ & $\mathrm{N}$ & $\mathrm{Y}$ & $\mathrm{Y}$ & $\mathrm{Y}$ & $\mathrm{N}$ & $\mathrm{Y}$ \\
\hline \begin{tabular}{|l|} 
Travel Advisory Radio \\
\end{tabular} & $\mathrm{Y}$ & $\mathrm{N}$ & $\mathrm{N}$ & $\mathrm{Y}$ & $\mathrm{Y}$ & $\mathrm{N}$ & $\mathrm{N}$ & $\mathrm{Y}$ \\
\hline Social Media Sites & $\bar{Y}$ & $\bar{Y}$ & $\bar{Y}$ & $\bar{Y}$ & $\bar{Y}$ & $\bar{Y}$ & $\bar{Y}$ & $\bar{Y}$ \\
\hline \multicolumn{9}{|c|}{ Type of Data Available: } \\
\hline Volume Counts & $\mathrm{Y}$ & $\mathrm{Y}$ & $\mathrm{Y}$ & $\mathrm{Y}$ & $\mathrm{Y}$ & $\mathrm{Y}$ & $\mathrm{Y}$ & $\mathrm{Y}$ \\
\hline Vehicle Classification & $\bar{Y}$ & $\bar{Y}$ & $\bar{Y}$ & $\bar{Y}$ & $\mathrm{Y}$ & $\mathrm{Y}$ & $\mathrm{Y}$ & $\mathrm{Y}$ \\
\hline Highway Classification & $\mathrm{Y}$ & $\mathrm{Y}$ & $\mathrm{Y}$ & $\mathrm{Y}$ & $\mathrm{Y}$ & $\mathrm{Y}$ & $\mathrm{Y}$ & $\mathrm{Y}$ \\
\hline $\mathrm{AADT}$ & $\mathrm{Y}$ & $\mathrm{Y}$ & $\mathrm{Y}$ & $\mathrm{Y}$ & $\mathrm{Y}$ & $\mathrm{Y}$ & $\mathrm{Y}$ & $\mathrm{Y}$ \\
\hline VMT & $\mathbf{N}$ & $\bar{Y}$ & $\mathrm{~N}$ & $\bar{Y}$ & $\mathrm{~N}$ & $\mathrm{Y}$ & $\mathrm{N}$ & $\mathrm{Y}$ \\
\hline Others & $\mathrm{Y}$ & $\mathrm{Y}$ & $\mathrm{Y}$ & $\mathrm{Y}$ & $\mathrm{Y}$ & $\mathrm{Y}$ & $\mathrm{Y}$ & $\mathrm{Y}$ \\
\hline Data format & PDF & $\mathrm{V}$ & $\mathrm{XLS}$ & PXV & PDF & $\mathrm{M}$ & G & PXK \\
\hline \multicolumn{9}{|c|}{ Improvement needed: } \\
\hline Websites & $\mathrm{Y}$ & \multicolumn{7}{|c|}{ Provide data in variety of presentation formats } \\
\hline External Database & $\mathrm{Y}$ & \multicolumn{7}{|c|}{ TMC Extranet needs faster approval process } \\
\hline Mobile App & $\mathrm{Y}$ & \multicolumn{7}{|c|}{ Provide hands-free App. } \\
\hline Travel Advisory Radio & $\mathrm{N}$ & & & & & & & \\
\hline Social M edia Sites & $\mathrm{N}$ & & & & & & & \\
\hline
\end{tabular}

Figure 2. Summary of comparison between DelDOT-TMC and selected states.

the three data possibilities $\mathrm{Y}, \mathrm{N}$ and $\mathrm{Y} / \mathrm{N}$ have been digitized in the format 1, 0.5 and 0 , respectively. Figures 3(a)-(d) below highlight the various comparators (C) in digitized format with the associated summative analysis represented as a comparator stack.

Further, Figure 4 highlights the data robustness and dissemination capacity which is the summative value across all comparators. This capacity measure in data robustness and dissemination provides a mechanism to compare each state TMC entity relative to the range of selected states. It shows that DelDOT-TMC performs well within the group of selected states, better than selected states of similar size and most selected states of larger size, and within an acceptable range relative to the neighboring states.

A unitless variable, Capacity Factor (Q), has been developed within this study to represent this relative comparison and is defined as follows:

1) Capacity Factor $(Q)$ equals the ratio of the average state TMC capacity (TC) to the maxium TMC comparator group stack capacity.

2) The maxium TMC comparator group stack capacity is equal to 5.

The following equation represents the caculation for Q: 


$$
\mathrm{Q}=\mathrm{TC} / 5
$$

Figure 5 below highlights the results of the capacity factor analysis. It is assumed that the maximum value for $\mathrm{Q}$ is 1.000; where the possible range for $\mathrm{Q}$ is between 0 and 1.000 . The group average $Q$ value is 0.847 . It can be seen that DelDOT-TMC performs well within the group at a $Q$ value of 0.875 realtive to the goup Q value of 0.847 . Further, DelDOT-TMC performs better than selected states of similar size and most selected states of larger size; where only Virginia performs better then DelDOT-TMC at a $Q$ value of 1.000. DelDOT TMC does not perform as well as selected neighboring states; however, it performs in an acceptable range relative to neighboring states; where it is well above the the linear trendline.

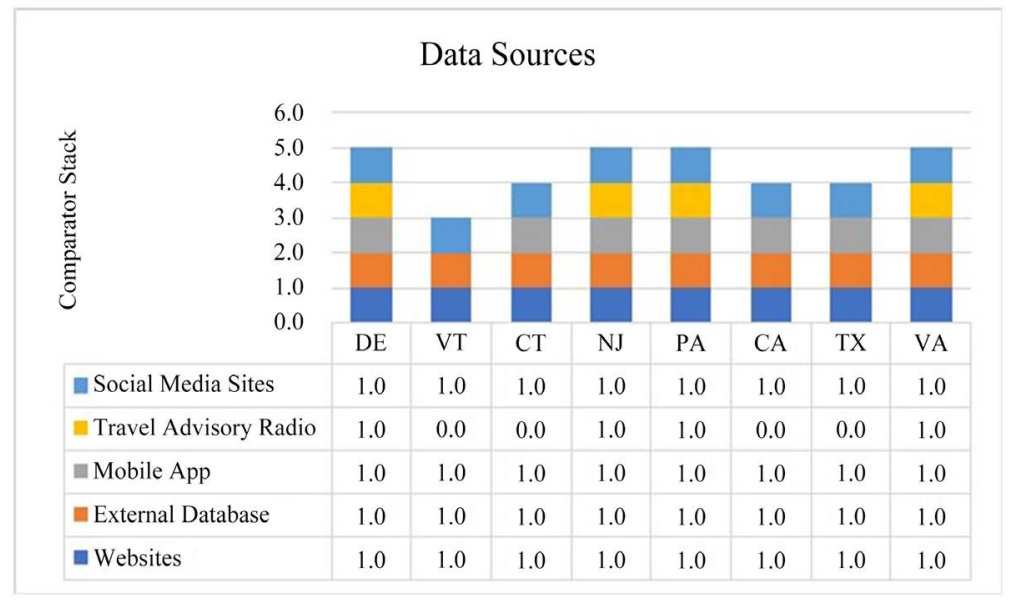

(a)

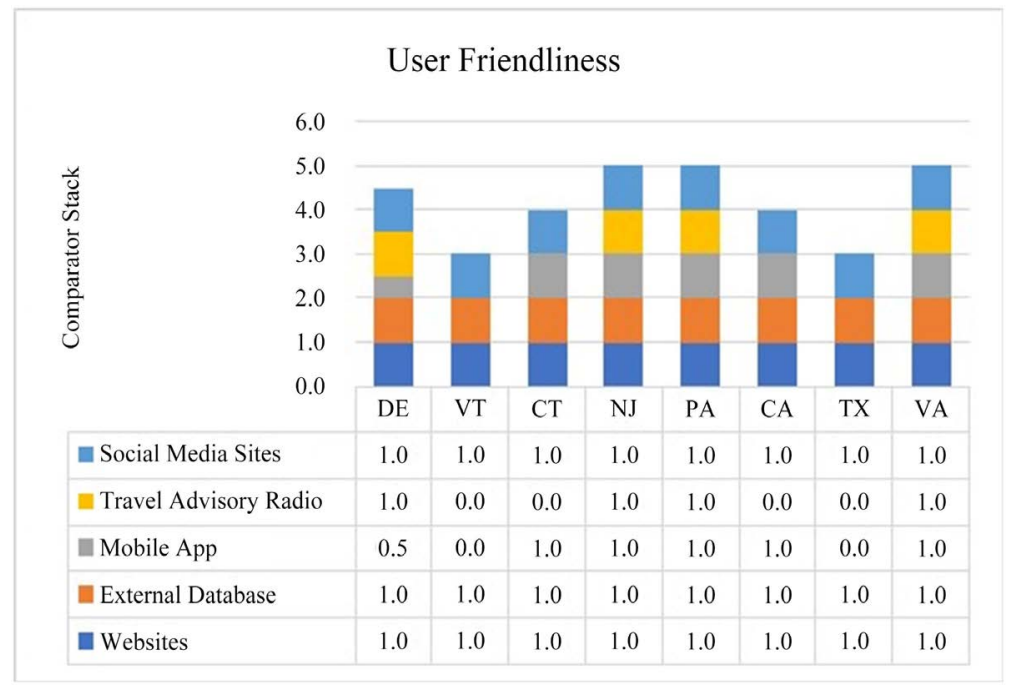

(b)

Figure 3. (a) Summary of comparator (Data Sources) between DelDOT-TMC and selected states; (b) Summary of comparator (User Friendliness) between DelDOT-TMC and selected states; (c) Summary of comparator (Assessibility) between DelDOT-TMC and selected states; (d) Summary of comparator (Type of Data Available) between DelDOT-TMC and selected states. 


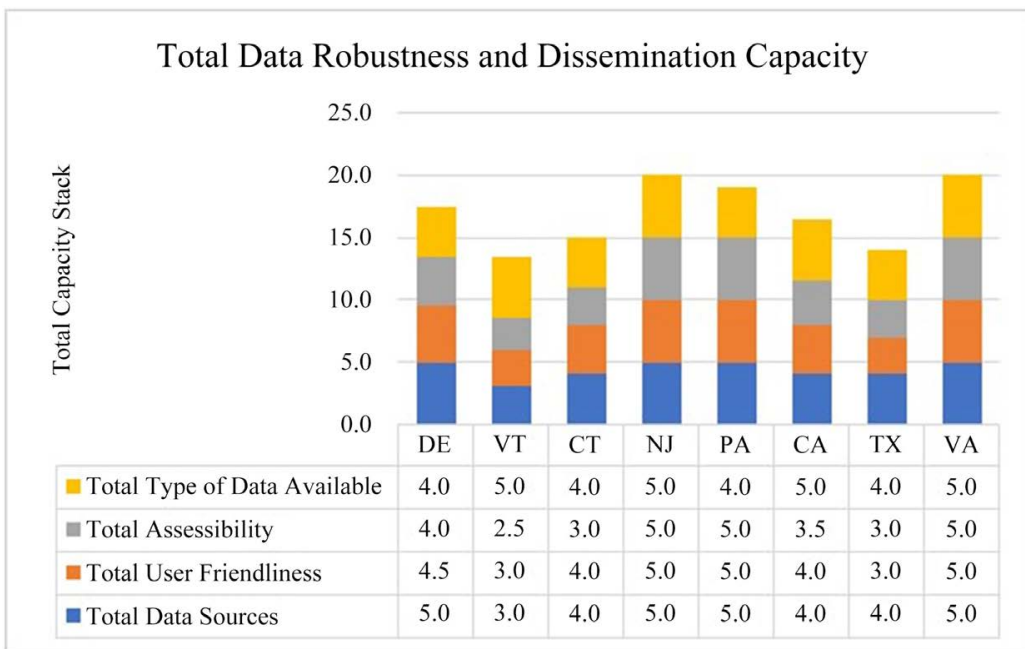

Figure 4. Summary of comparator (Total Data Robustness and Dissemination Capacity) between DelDOT-TMC and selected states.

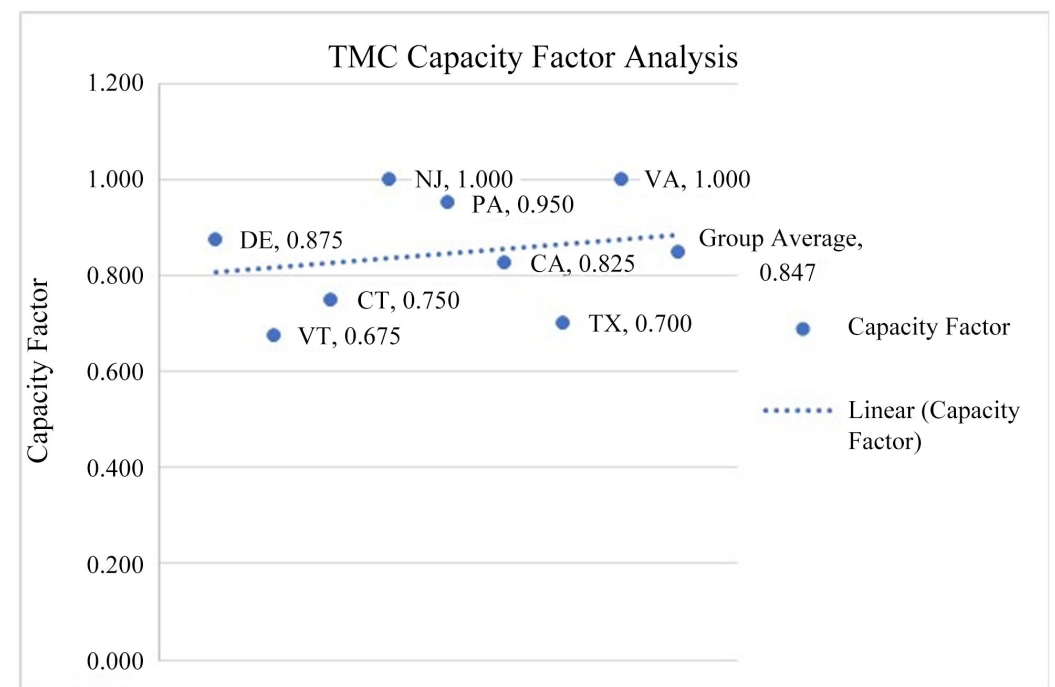

Figure 5. Capacity factor analysis for DelDOT-TMC and selected states.

\section{Conclusions}

There is a tremendous need for transportation data in order to conduct research on the various aspects of highway performance. Traffic and roadway weather information is not only crucial for professionals, but for the general public as well. DelDOT-TMC is responsible for providing real-time traffic and roadway weather information through various sources. Thus, this study provided an indepth examination of the history and the overall responsibility of DelDOTTMC.

It was discovered that DelDOT-TMC uses the latest equipment, technology, software, and devices that are installed throughout the state of Delaware to collect a variety of traffic, roadway weather, and hydrological data. Traffic data included highway classification, vehicle classification, and volume count. Real-time roadway weather data includes air temperature, barometric pressure, relative 
humidity, precipitation type and volume, pavement temperature as well as subsurface temperature. Hydrological data studies focused on stream and river depths, water velocity, and tide height. Overall, these are the three main types of data that are collected and disseminated by DelDOT-TMC.

DelDOT-TMC used various sources and websites to display traffic and roadway weather information such as the public websites, TMC Extranet, the DelDOT Mobile App, travel advisory radio, and social media sites. However, most of the mentioned websites and application provided limited information. For example, the public website used interactive maps to provide real-time traffic information; however, historical data were unavailable. Also, users were presented with the selection to view traffic and weather information, but the option to download or export the given data was unavailable. It was also discovered that the DelDOT-TMC websites and mobile application presented the data in PDF files or through the interactive maps.

After the comparative study, the results showed that there were some similarities and differences between the states TMC. It was discovered that DelDOTTMC and all of the selected states had a variety of data equipment and collection methods to gather traffic data. In most cases, each of the state websites was easily accessible and user-friendly. Although some of the state sources were more detailed than others, all of the states provided real-time traffic data through various sources including websites, mobile applications, travel advisory radios, and social media sites. The comparison of the selected state TMC entities also provided two very noticeable differences when compared to DelDOT-TMC. First, the DelDOT-TMC Extranet website required that potential users register before they are provided access to the department's website and database; however, TMC Extranet approval process can take up to a couple of weeks before the application is approved. Compared to the selected states, DelDOT-TMC Extranet was the only website that had an extremely long approval process. Also, the site provides historical traffic count information exclusively in PDF files; where, different presentation formats are not offered. The second noticeable difference was the travel advisory radio, which is a part of the mobile application. DelDOT Mobile App offers drivers with real-time travel information through interactive maps. Although this is a useful tool, it does not provide users with a hands-free option. Thus, using the mobile App while driving can be very distracting and dangerous. Not to mention that Delaware has a hands-free law, which prevents users from accessing their smartphone application while driving.

A unitless variable, Capacity Factor (Q), was developed within this study to represent this relative comparison. This study shows that DelDOT-TMC performs well within the group of selected states and better than selected states of similar size and most selected states of larger size; where only Virginia performs better then DelDOT-TMC. DelDOT-TMC does not perform as well as selected neighboring states; however, it performs in an acceptable range relative to neighboring states. 


\section{Acknowledgements}

This work was partially supported by the Delaware Center for Transportation (DCT) co-sponsored by the University of Delaware and the Delaware Department of Transportation. The authors express their sincere gratitude to DCT for providing their extensive data sources.

\section{Conflicts of Interest}

The authors declare no conflicts of interest regarding the publication of this paper.

\section{References}

[1] Hua, J. and Faghri, A. (1994) Applications of Artificial Neural Networks to Intelligent Vehicle-Highway Systems. Transportation Research Record, 1453, 83.

[2] Faghri, A. and Chakroborty, P. (1994) Development and Evaluation of a Statistically Reliable Traffic Counting Program. Transportation Planning and Technology, 18, 223-237. https://doi.org/10.1080/03081069408717545

[3] Faghri, A., Glaubitz, M. and Parameswaran, J. (1996) Development of Integrated Traffic Monitoring System for Delaware. Transportation Research Record, 1536, 40-44. https://doi.org/10.1177/0361198196153600106

[4] Ozden, A., Faghri, A. and Li, M. (2016) Using Knowledge-Automation Expert Systems to Enhance the Use and Understanding of Traffic Monitoring Data in State DOTs. Procedia Engineering, 145, 980-986. https://doi.org/10.1016/j.proeng.2016.04.127

[5] Li, M. and Faghri, A. (2016) Applying Problem-Oriented and Project-Based Learning in a Transportation Engineering Course. Journal of Professional Issues in Engineering Education and Practice, 142, Article ID: 04016002. https://doi.org/10.1061/(ASCE)EI.1943-5541.0000274

[6] Zhou, X., Rouphail, N. and Li, M. (2011) Analytical Models for Quantifying Travel Time Variability Based on Stochastic Capacity and Demand Distributions. Transportation Research Board 90 th Annual Meeting, Washington DC, 23-27 January 2011.

[7] Jia, A., Zhou, X., Li, M., Rouphail, N. and Williams, B. (2011) Incorporating Stochastic Road Capacity into a Day-to-Day Traffic Simulation and Traveler Learning Framework: Model Development and Case Study. Transportation Research Record: Journal of the Transportation Research Board, 2254, 112-121. https://doi.org/10.3141/2254-12

[8] Li, M., Zhou, X. and Rouphail, N. (2011) Quantifying Benefits of Traffic Information Provision under Stochastic Demand and Capacity Conditions. Intelligent Transportation Systems (ITSC), 2011 14th International IEEE Conference, Washington DC, 5-7 October 2011. https://doi.org/10.1109/ITSC.2011.6082843

[9] Li, M., Rouphail, N.M., Mahmoudi, M., Liu, J. and Zhou, X. (2017) Multi-Scenario Optimization Approach for Assessing the Impacts of Advanced Traffic Information under Realistic Stochastic Capacity Distributions. Transportation Research Part C: Emerging Technologies, 77, 113-133. https://doi.org/10.1016/j.trc.2017.01.019

[10] Li, M., Zhou, X. and Rouphail, N.M. (2017) Quantifying Travel Time Variability at a Single Bottleneck Based on Stochastic Capacity and Demand Distributions. Journal of Intelligent Transportation Systems. Technology, Planning, and Operations, 21, 
79-93. https://doi.org/10.1080/15472450.2016.1163639

[11] Li, M., Zhou, X. and Rouphail, N. (2011) Planning-Level Methodology for Evaluating Traveler Information Provision Strategies under Stochastic Capacity Conditions. Transportation Research Board 90 th Annual Meeting, Washington DC, 23-27 January 2011.

[12] Berzina, L., Faghri, A., Shourijeh, M.T. and Li, M. (2014) Development of a PostProcessing Automation Procedure for the GPS-Based Travel Time Data Collection Technique. Journal of Transportation Technologies, 4, 63-71.

https://doi.org/10.4236/jtts.2014.41006

[13] Berzina, L., Faghri, A., Shourijeh, M. and Li, M. (2013) Evaluation of Travel Time Data Collection Techniques: A Statistical Analysis. International Journal of Traffic and Transportation Engineering, 2, 149-158. https://doi.org/10.5923/j.ijtte.20130206.03

[14] Hamad, K., Faghri, A. and Li, M. (2015) Forecasting Model for Vehicular Demand: An Alternative Methodology in the Context of Developing Countries. The Journal of Developing Areas, 49, 125-143. https://doi.org/10.1353/jda.2015.0006

[15] Laghaei, J., Faghri, A. and Li, M. (2015) Impacts of Home Shopping on Vehicle Operations and Greenhouse Gas Emissions: Multi-Year Regional Study. International Journal of Sustainable Development \& World Ecology, 23, 381-391. https://doi.org/10.1080/13504509.2015.1124471

[16] Suarez, R., Faghri, A. and Li, M. (2014) Evaluation of the Accuracy and Automation of Travel Time and Delay Data Collection Methods. Journal of Transportation Technologies, 4, 72-83. https://doi.org/10.4236/jtts.2014.41007

[17] Frey, R., Faghri, A. and Li, M. (2014) Development of an Expert System for Effective Countermeasure Identification at Rural Unsignalized Intersections. Transportation Research Board 93rd Annual Meeting, Washington DC, 12-16 January 2014.

[18] DelDOT (2017) Delaware Department of Transportation Integrated Transportation Management Strategic Plan. DelDOT, Dover.

[19] Wahed, M., Faghri, A. and Li, M. (2017) An Innovative Simulation Model for the Operations of a Multipurpose Seaport: A Case Study from Port of Wilmington, USA. International Journal of Simulation and Process Modelling, 12, 151. https://doi.org/10.1504/IJSPM.2017.083530

[20] Taromi, R., DuRoss, M., Chen, B., Faghri, A., Li, M. and DeLiberty, T. (2015) A Multi-Objective Land Development Optimization Model: The Case of New Castle County, Delaware. Transportation Planning and Technology, 38, 277-304. https://doi.org/10.1080/03081060.2014.997450

[21] Vaughan, M.L., Faghri, A. and Li, M. (2017) An Interactive Expert System Based Decision Making Model for the Management of Transit System Alternate Fuel Vehicle Assets. Intelligent Information Management, 9, 1-20. https://doi.org/10.4236/iim.2017.91001

[22] Vaughan, M.L., Faghri, A. and Li, M. (2018) Knowledge-Based Decision-Making Model for the Management of Transit System Alternative Fuel Infrastructures. International Journal of Sustainable Development \& World Ecology, 25, 184-194. https://doi.org/10.1080/13504509.2017.1333541

[23] Shahpar, A., Faghri, A. and Li, M. (2018) Emission and Life-Cycle Assessment of Alternative-Fuel Buses: A Case Study of the Delaware Authority of Regional Transit. International Journal of Sustainable Development \& World Ecology, 25, 290-302. https://doi.org/10.1080/13504509.2017.1390794

[24] Li, M., Faghri, A., Ozden, A. and Yue, Y. (2017) Economic Feasibility Study for 
Pavement Monitoring Using Synthetic Aperture Radar-Based Satellite Remote Sensing: Cost-Benefit Analysis. Transportation Research Record: Journal of the Transportation Research Board, No. 2645, 1-11. https://doi.org/10.3141/2645-01

[25] Schroeder, B.J., Cunningham, C.M., Findley, D.J., Hummer, J.E. and Foyle, R.S. (2010) Manual of Transportation Engineering Studies. Institute of Transportation Engineers, Washington DC.

[26] Vandervalk-Ostrander, A. (2009) AASHTO Guidelines for Traffic Data Programs. AASHTO, Washington DC. 